\title{
AN EXPERIMENTAL AND NUMERICAL STUDY OF MOISTURE TRANSPORT AND MOISTURE-INDUCED STRAIN IN FAST-GROWN SITKA SPRUCE
}

\author{
Conan O'Ceallaigh ${ }^{1, \diamond}$, Karol Sikora', Daniel McPolin ${ }^{3}$, Annette M. Harte ${ }^{1}$
}

\begin{abstract}
The use of-fast-grown timber in the manufacture of engineered wood products is increasing; however, the fast growth rate results in a low-density timber that is susceptible to significant swelling and shrinkage deformations under changing moisture content. The current study focuses on the characterisation of the moisture diffusion and swelling/shrinkage of fast-grown Sitka spruce and the prediction of the moisture-induced strain development in Sitka spruce glulam beams under variable humidity cycles. Moisture content evolution and swelling/shrinkage coefficients were measured and the longitudinal swelling/shrinkage was found to be significantly greater than for slow-grown timber. Sitka spruce glued-laminated beams were subjected to controlled relative humidity cycling for 52 weeks and the moisture distribution and moisture-induced strains were measured continuously. Coupled moisturedisplacement numerical models, incorporating the experimentally measured material parameters were developed. The effect of the glue-line was found to have an insignificant effect on moisture transport, however, the material orientation greatly influenced the predicted moisture-induced strain. Accurately mapping the material orientation produced significantly better predictions of the experimental results over the 52-week period.
\end{abstract}

Keywords: Adsorption, desorption, finite element analysis, glued laminated timber, long-term moisture transport, moisture diffusion.

\section{INTRODUCTION}

The use of timber in the construction industry has been steadily growing in recent times. This increase is partly due to an increasing need for more sustainable construction materials. Timber is a naturally-grown sustainable material which is not only aesthetically pleasing but also demonstrates a high strength to weight ratio making it an excellent material to use in the construction industry. The use of this material has been steadily increasing in recent times due to advances in engineered wood products (EWPs) and increased focus on reducing the environmental impact of construction materials. Predominantly, slow-grown timber has been used to manufacture EWPs such as glued laminated timber and cross-laminated timber, however, with increasing forest intensification significant quantities of fast-grown timber are coming on stream and their potential use in EWPs needs to be investigated. The fast growth rate results in a low-density timber that is susceptible to significant swelling and shrinkage deformations in the longitudinal direction under changing moisture content. Swelling and shrinkage deformations in the longitudinal direction of fast-grown timber can be much greater than that observed in slow-grown timber of the same species.

This study examines the behaviour of this fast-grown material in EWPs subjected to fluctuating

${ }^{1}$ College of Engineering \& Informatics \& Ryan Institute, National University of Ireland Galway, University Rd., Galway,

Ireland. annette.harte@nuigalway.ie

${ }^{2}$ Faculty of Engineering and Information Sciences, University of Wollongong in Dubai, Dubai, UAE.

karolsikora@uowdubai.as.ae

${ }^{3}$ School of Planning, Architecture and Civil Engineering, Queen's University Belfast, University Road, Belfast, UK.

d.mcpolin@qub.ac.uk

•Corresponding author: conan.oceallaigh@nuigalway.ie

Received: 17.10.2017 Accepted: 29.07.2018 
relative humidity environments. Timber is a hygroscopic material and, as such, its moisture content will equilibrate to the environment in which it is placed. It will absorb or desorb moisture as required to obtain an equilibrium moisture content. This is important to consider when designing timber structures as moisture content is an important parameter affecting durability, shrinkage/swelling, modulus of elasticity and even strength (Skaar 1987). As a result, exposure to moisture variations over a long period of time is of great significance to the performance of in-service timber elements and EWPs. When stressed under load, significant long-term effects or creep effects can lead to premature failure or excessive deflection, however, even in an unloaded situation, strains can develop during moisture content variations, causing cracks parallel to the grain and weakening the integrity of the element (Svensson and Toratti 2002, Fragiacomo et al. 2011, Zongying et al. 2016). Reliable prediction of moisture transport and moisture content within timber is important for all structural and EWPs during their service life. The material properties determining the rate and magnitude of moisture transport varies with species. In order to accurately model the response of timber elements in a variable climate, species-specific material properties must be determined.

At a given relative humidity, the species of timber has no significant effect on the moisture content of the timber. This is primarily due to the similar cell wall structure within all species (Wadsö 1993). Many models have been created to determine the average equilibrium moisture content of timber as a function of the relative humidity and temperature (Hailwood and Horrobin 1946, Simpson 1973, Avramidis 1989, Sargent et al. 2010, Simo-Tagne et al. 2016), however, these models do not consider the moisture content hysteresis of timber during adsorption and desorption. Merakeb et al. (2009) and Patera et al. (2015) have investigated and modelled the influence of the hysteresis effect on moisture transport in timber. Both studies accurately modelled hysteresis loops ranging between the main adsorption and desorption curves and were validated against experimental results. This suggests that models presenting average equilibrium moisture content as a function of relative humidity and omitting the hysteresis effect can lead to significantly different predictions. Many studies have experimentally determined the hysteresis loop for timber, however, to the authors' knowledge, none have been specifically determined for fast-grown Sitka spruce.

The dimensional stability or swelling/shrinkage characteristics of timber during moisture content change are dependent on species. Ormarsson and Cown (2004) compared the swelling/shrinkage characteristics of two species, namely, radiate pine and Norway spruce. They reported that the swelling/shrinkage coefficient of Norway spruce was significantly greater than the swelling/shrinkage coefficient of Radiata pine in the radial and tangential directions. The longitudinal swelling/shrinkage coefficient reported for Norway spruce was much less than that reported for radiata pine. It is evident that species is an important parameter when determining swelling/shrinkage coefficients, however, even within species there can also be an effect due to growth conditions. Bengtsson (2001) investigated the variations between the swelling/shrinkage coefficients from a well-documented fast-grown and slowgrown stand of Norway spruce. Similar measurements were taken from both the fast and slow-grown timber. It was found that the swelling/shrinkage coefficients for the radial and tangential directions were significantly larger for the slow-grown timber; however, the opposite was seen in the longitudinal direction with a significantly larger coefficient observed for the fast-grown stand.

Moisture is transferred between timber and its surrounding environment under variable climate conditions. Many authors have developed analytical and numerical models which examine the flow of moisture through timber cross sections and most importantly, the mechanical response due to this moisture content change (Hanhijärvi 1995b, Svensson and Toratti 2002, Fragiacomo et al. 2011). The movement of moisture through timber sections has been successfully described using Fick's Law of mass diffusion (Toratti 1993. Hanhijärvi 1995b, Fortino et al. 2009) which can be seen in Equation 1 in its three-dimensional form.

$$
\frac{\partial \phi}{\partial t}=D_{x}\left(\frac{\partial^{2} \phi}{\partial x^{2}}\right)+D_{y}\left(\frac{\partial^{2} \phi}{\partial y^{2}}\right)+D_{z}\left(\frac{\partial^{2} \phi}{\partial z^{2}}\right)
$$

\section{Where:}

- $\mathbf{x}, \mathbf{y}, \mathbf{z}$ - material directions corresponding to the radial, tangential and longitudinal 
respectively

- D - diffusion coefficient $\left(\mathrm{m}^{2} / \mathrm{s}\right)$

- $\phi$ - moisture concentration $\left(\mathrm{kg} / \mathrm{m}^{3}\right)$

The rate of moisture diffusion within the timber is a slow process driven by moisture gradients and depends on the diffusion coefficient. Diffusion coefficients in the principal material directions have been reported for various species of timber. Many authors report moisture dependent diffusion coefficients, which make Fick's law non-linear, and have successfully validated these coefficients against experimental results (Toratti 1993, Hanhijärvi 1995b, Fortino et al. 2009).

The surface emissivity is an important factor determining the rate of moisture transport from the environment across the surface of the timber and into the bulk material. The emissivity of a surface is a function of the air flow characteristics such as velocity, moisture content and temperature (Siau and Avramidis 1996). Previous studies of moisture diffusion, which use a prediction model with moisture dependent surface emissivity coefficients, and, which neglect velocity of the air flow, have been validated against experimental results (Hanhijärvi 1995b, Fortino et al. 2009).

Adhesive glue-lines in large engineered timber elements are often neglected when analysing moisture diffusion. The effect of the adhesive glue-line may hinder moisture transport within an element. Srpčič et al. (2009) modelled the glue-line at two extremes; first, the glue-line was modelled as a completely waterproof surface with a diffusion coefficient of zero and this was then compared to a model where the glue-line had the same diffusion coefficient as the timber. They found that the moisture content distribution in the outer laminations was affected significantly by the modelling approach and the differences within the inner laminations were almost negligible. The differences in moisture-induced strain were not examined. This area is receiving more attention due to the importance of moisture effects in EWPs and the significant strains which can result in a variable climate (Gereke and Niemz 2010, Wimmer et al. 2013).

This study is undertaken to examine experimentally and numerically, the interaction between fast-grown Sitka spruce and the surrounding environment. Fast-grown Sitka spruce is characterised as a low-density timber with large ring widths and a high juvenile wood content as a result of the climate conditions in Ireland (Bourke et al. 2001, Raftery and Harte 2014). These characteristics make it susceptible to distortion when dried to low moisture contents. Typically, in-service timber elements can be subject to high relative humidity conditions when used externally or in a moisture fluctuating environment. On the other hand, timber elements used internally can be subjected to relative humidity conditions much lower than $65 \%$ especially when buildings are heated during the winter months. To utilise this fast-grown material in EWPs, its swelling/shrinkage behaviour in variable climatic conditions must be examined. In this paper, a series of experiments, designed to examine the flow of moisture and moisture-induced strain development within glued laminated timber beams manufactured from fast-grown Sitka spruce, is presented. Preliminary experiments involve small clear specimens of Sitka spruce to determine the equilibrium moisture content as a function of relative humidity and the swelling/shrinkage characteristics in a climate-controlled room. Structural size glued laminated beams are then placed in a variable climate stepped between $65 \% \pm 5 \%$ relative humidity to $90 \% \pm 5 \%$ relative humidity in a repeating 8 -week cycle over 52 weeks. The moisture content and moisture-induced strains are monitored during these cycles. Finally, numerical models to predict moisture content distribution and moisture-induced strains are developed implementing experimentally determined parameters, and are compared with experimentally measured results. The influence of the annual ring orientation and the glue-line on the flow of moisture and moisture-induced strain development within glued laminated beams is also examined.

\section{MATERIALS AND METHODS}

A series of experiments was designed to determine moisture-dependent material properties and investigate the flow of moisture within fast-grown Sitka spruce elements. The material used in this study was sourced in Ireland. This species has an average rotation length of only 35-40 years (Raftery 
and Harte 2014). The regional climate conditions and silvicultural practices often result in a fast-grown, low-density timber with a high proportion of juvenile wood content. The following series of tests were initiated:

- Moisture content hysteresis measurement using gravimetric method

- Determination of swelling/shrinkage coefficients

- Moisture content distribution measurement in glulam using resistance method

- Measurement of moisture-induced strains on full-scale glued laminated beams.

The preliminary experiments are used to investigate the hysteresis effect and swelling/shrinkage characteristics of small clear samples. The remaining experiments focus on moisture content distribution and moisture-induced strains within larger timber elements. This experimental data will be incorporated in numerical models to accurately predict the behaviour of this material under variable moisture content conditions.

\section{Material characterisation}

In order to determine the moisture content hysteresis in fast-grown Sitka spruce, small clear samples were prepared. Specimens of two sizes were used: cubes measuring $30 \times 30 \times 30 \mathrm{~mm}^{3}$ and sticks measuring 20x20x150 $\mathrm{mm}^{3}$. These specimens were cut from boards of fast-grown Sitka spruce timber. An equal proportion of specimens was taken from boards containing pith and boards with no pith to ensure the sample was representative of construction timber produced in Ireland. In total, thirty cubes and sixty sticks specimens were produced. Both types of specimens were used to monitor the absorption and desorption of moisture when placed in a controlled climate chamber at a series of relative humidity steps from $30 \%-90 \%$ relative humidity. The controlled climate chamber system can maintain a relative humidity from $10 \%$ to $95 \%$ with an accuracy of $\pm 5 \%$ and the temperature from $10^{\circ} \mathrm{C}$ to $40^{\circ} \mathrm{C}$ with an accuracy of $\pm 2{ }^{\circ} \mathrm{C}$. Initially, the adsorption phase was measured at increasing steps of $30 \%, 50 \%, 60 \%$, $70 \%, 80 \%$ and $90 \%$ relative humidity. Once the adsorption phase had been completed, the samples were then soaked in water for seven days to ensure that the moisture content was greater than the fibre saturation point. The process was repeated in reverse from $90 \%-30 \%$ relative humidity to observe the desorption phase. This provided the full moisture content hysteresis of fast-grown Sitka spruce.

The stick specimens were used to monitor the swelling and shrinkage strains in the longitudinal, tangential and radial directions at each relative humidity step. The stick specimens $\left(20 \times 20 \times 150 \mathrm{~mm}^{3}\right)$ were elongated along the longitudinal direction. The reason for using this type of elongated specimen was to ensure that measurable deformations were induced in the longitudinal direction as the longitudinal deformation is about fifty times smaller than the deformation measured in the tangential direction for the same change in moisture content (Bengtsson 2001). The dimensions of the stick specimens were measured when the equilibrium moisture content was achieved at each relative humidity step allowing a graph of strain vs moisture content to be plotted. The swelling/shrinkage coefficient was measured as the slope of the strain vs moisture content graph (Equation 2).

$$
\alpha=\frac{\Delta \varepsilon}{\Delta u}
$$

Where:

- $\quad \boldsymbol{\alpha}$ - shrinkage/swelling coefficient (\%/\%)

- $\Delta \boldsymbol{\varepsilon}$ - change in total strain (\%)

- $\quad \Delta \mathbf{u}$ - change in moisture content $(\%)$ 


\section{Moisture content distribution measurement in glulam using resistance method}

In-situ moisture content measurements within timber in variable climates can be of great interest to engineers and researchers alike. There are various methods and instruments used to determine moisture content other than the time-consuming oven-dry method, which is often impractical in many cases. The resistance method used in this study is one such method that utilises the relationship between moisture content and the electrical properties of timber. In this method, a voltage is applied across two moisture pins inserted into the timber and the resistance is measured. This resistance can be calibrated against moisture content. This method works best between 6-30\% moisture content (Dai and Ahmet 2001). In studies by Forsén and Tarvainen (2000) and Taylor and West (1990), the species and type of moisture pin used were shown to have a significant influence when measuring moisture content using the resistance method.

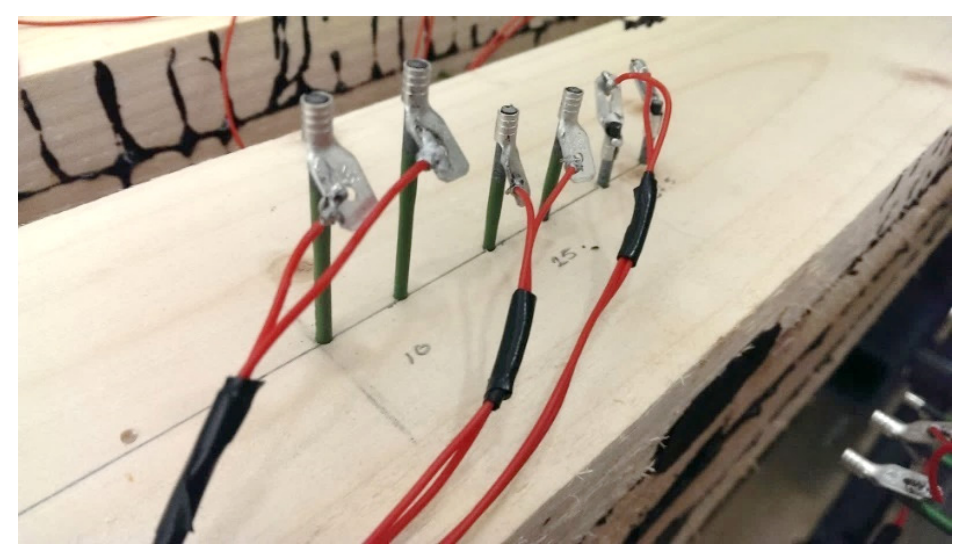

Figure 1: Pins inserted at various depths in beams.

Calibrated was performed on Teflon insulated moisture probes in fast-grown specimens and each moisture probe consisting of two pins was inserted into structural size glued laminated beams as seen in Figure 1. The $2300 \mathrm{~mm}$ long beams with cross-sectional dimensions $125 \mathrm{~mm}$ x $98 \mathrm{~mm}$, comprise four laminations bonded using a PRF adhesive. These beams were placed in a variable climate chamber and stepped between $65 \% \pm 5 \%$ and $90 \% \pm 5 \%$ relative humidity in an 8 -week cycle at a constant temperature of $20^{\circ} \mathrm{C} \pm 2{ }^{\circ} \mathrm{C}$. It is important to note that the ends and bottom surface of these beams are sealed to prevent moisture movement through these surfaces. This limits the moisture transport through both sides of the beam and the top surface. The waterproof sealant replicates exposure conditions commonly found in construction whereby the ends of beams and one face of the beam are not exposed. These probes were strategically positioned to measure the change in moisture content through the cross-section in a variable climate. Four sets of moisture content measurement at each of the eleven specified probe locations (MC1-MC11) as shown in Figure 2 were recorded. Pairs of pins were inserted perpendicular to the grain at a spacing of $15 \mathrm{~mm}$ in order to replicate the test set-up during the calibration of the pins. Probes penetration depths were selected to ensure that measurements above and below a glue-line were included so that the influence of the glue-line could be examined. 


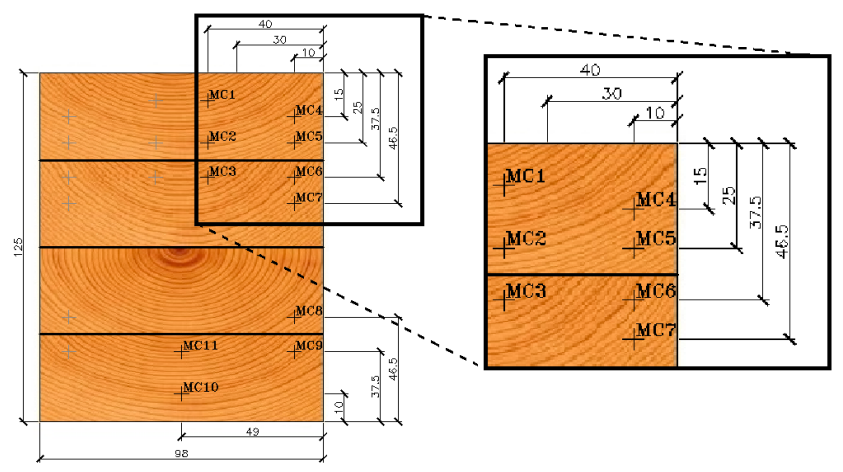

Figure 2: Moisture probe positions.

\section{Moisture-induced strains on full scale glued laminated beams}

It is well known that below the fibre saturation point, timber swells and shrinks as moisture content increases and decreases, respectively. These moisture-induced dimensional changes are not equal in all directions. To investigate the dimensional stability of fast-grown glued laminated timber, four structural size specimens with cross-section dimensions of $98 \mathrm{~mm} \times 125 \mathrm{~mm}$ were placed in the variable climate chamber to monitor strain development with changing moisture content. Each beam was monitored with four electrical resistance strain (ERS) gauges, aligned in the longitudinal direction on the tension and compression faces and perpendicular to the grain on the side of the specimens. The strain was monitored using a Campbell Scientific CR1000 data logger, which recorded the strain in each gauge every 60 minutes. The glued laminated specimens were supported at $200 \mathrm{~mm}$ centres on low-friction polytetrafluoroethylene (PTFE) plates to ensure strains due to self-weight were negligible. The low-friction PTFE plates ensure that the beams could swell and shrink freely as necessary. The beams were initially conditioned to approximately $12 \%$ moisture content in a controlled climate with a relative humidity of $65 \% \pm 5 \%$ and a temperature of $20^{\circ} \mathrm{C} \pm 2{ }^{\circ} \mathrm{C}$. They were then placed in a variable climate chamber where they remained at a constant $65 \% \pm 5 \%$ for 3 weeks prior to cycling between $65 \% \pm 5 \%$ and $90 \% \pm 5 \%$ relative humidity in 8 -week cycles. Temperature remained constant at $20^{\circ} \mathrm{C}$ $\pm 2{ }^{\circ} \mathrm{C}$ throughout.

\section{EXPERIMENTAL RESULTS}

\section{Material characterisation results}

The results in Figure 3 show the moisture content of fast-grown Sitka spruce as a function of relative humidity during the adsorption and desorption phases. It is important to note that the temperature remained constant throughout the experiment at $20^{\circ} \mathrm{C} \pm 2{ }^{\circ} \mathrm{C}$. The moisture content hysteresis curve represents the mean moisture content of all 90 samples (cubes and sticks) at a given relative humidity step. The value at $100 \%$ relative humidity was assumed to be the moisture content corresponding to the maximum measured strain. The standard deviation associated with the moisture content measurement varied between 0,09 and $0,42 \%$. 


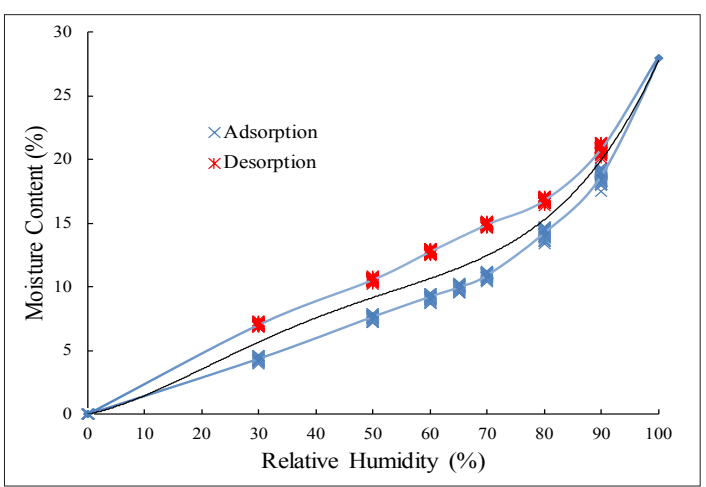

Figure 3: Moisture content hysteresis for Sitka spruce at $20^{\circ} \mathrm{C}$.

Many models such as the Hailwood-Horrobin and GAB (Guggenheim-Andersen-de Boer) isotherms have been developed and utilised to describe the sorption behaviour of wood (Simpson 1973, Avramidis 1989, Sargent et al. 2010, Simo-Tagne et al. 2016). In this study, a $4^{\text {th }}$ order polynomial was found to have the best fit to the experimental data and is used to express the moisture content as a function of relative humidity at a temperature of $20^{\circ} \mathrm{C}$ (Equation 3).

$$
u(x)=r_{1} x^{4}+r_{2} x^{3}+r_{3} x^{2}+r_{4} x+r_{5}
$$

Where:

- $\quad \mathbf{x}$ - relative humidity $(\%)$

- $\quad \mathbf{r}_{1}-\mathbf{r}_{5}$ - shape factors/coefficients for the adsorption and desorption curve (Table 1).

Table 1: Shape factors for the adsorption and desorption curve.

\begin{tabular}{|c|c|c|}
\cline { 2 - 3 } \multicolumn{1}{c|}{} & Adsorption & Desorption \\
\hline $\mathrm{r}_{1}$ & $1,32 \times 10^{-6}$ & 0 \\
\hline $\mathrm{r}_{2}$ & $-2,10 \times 10^{-4}$ & $5,02 \times 10^{-5}$ \\
\hline $\mathrm{r}_{3}$ & $1,09 \times 10^{-2}$ & $-6,27 \times 10^{-3}$ \\
\hline $\mathrm{r}_{4}$ & $-2,90 \times 10^{-2}$ & $4,00 \times 10^{-1}$ \\
\hline $\mathrm{r}_{5}$ & $5,87 \times 10^{-3}$ & $-1,25 \times 10^{-1}$ \\
\hline
\end{tabular}

The average result compares well to models in the literature (Hailwood and Horrobin 1946, Simpson 1973, Avramidis 1989). The hysteresis loop, shown in Figure 3, gives an accurate range of moisture content between the lower adsorption curve and the upper desorption curve. The hysteresis loop will be used to model the moisture content transition from one curve to the other in a variable climate. Further characterisation of the material is required to examine equilibrium moisture contents above and below this temperature.

In Figure 4, the average strain at each relative humidity step is plotted against the average moisture content, for each of the material directions. There is no distinction made between strains during the adsorption phase and the desorption phase. Statistical tests have shown that there was no statistically significant difference at the 0,95 significance level $(\alpha=0,5)$ between the mean strains measured during adsorption and those measured during the desorption phase. The observed longitudinal swelling/shrinkage coefficient is much less than the observed tangential and radial swelling/shrinkage 
coefficients as expected.

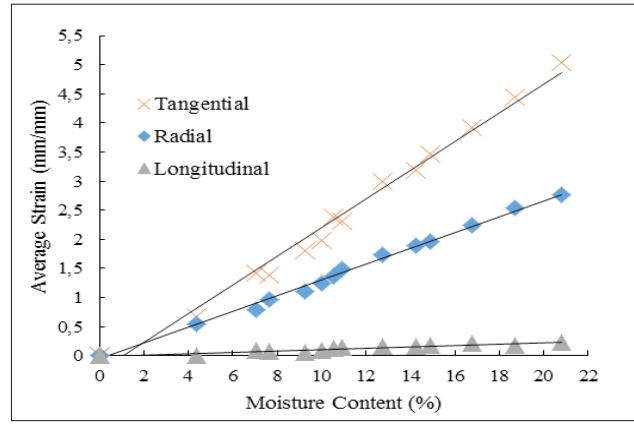

Figure 4: Swelling/shrinkage results.

In Table 2, the mean swelling/shrinkage coefficients for fast-grown Sitka spruce in the tangential, radial and longitudinal direction are presented. These swelling/shrinkage coefficients are calculated using the slope of the regression lines fitted to the data in Figure 4 (Equation 2).

Table 2: Mean swelling/shrinkage coefficients.

\begin{tabular}{|c|c|}
\cline { 2 - 2 } \multicolumn{1}{c|}{} & $\begin{array}{c}\text { Swelling/Shrinkage } \\
\text { Coefficient }(\boldsymbol{\alpha})\end{array}$ \\
\hline Tangential & 0,2525 \\
\hline Radial & 0,1371 \\
\hline Longitudinal & 0,0122 \\
\hline
\end{tabular}

The radial and tangential results are similar to many reported results in the literature, however, the swelling/shrinkage coefficient of $0,0122(\% / \%)$ in the longitudinal direction is larger than expected. This is thought to be as a result of the fast growth conditions, large ring widths and high juvenile wood content of this species. This result is similar to the larger longitudinal swelling/shrinkage coefficient observed by Bengtsson (2001) when examining swelling/shrinkage coefficients in fast-grown trees.

\section{Moisture content distribution measurement in glulam results}

The moisture content at each probe position for the instrumented beams has been monitored and the results of the first 52 weeks are presented together with the recorded relative humidity. The moisture content rises and decreases in response to the changing relative humidity with each cycle. The moisture probes close to the surface, experience a rapid change due to the high initial moisture gradient created as a result of the change in relative humidity. The moisture probes nearer to the center of the beam experience less change in moisture content as expected, however an increasing trend is observed with repeated moisture cycles within moisture probes closer to the centre. The mean results from MC1, MC2 and MC3 are presented in Figure 5. The moisture content with time at these moisture probe positions is primarily as a function to the depth at which these probes are placed; however, these results also raise the question of the PRF glue-line used during the manufacturing process of this beam and its effect on the moisture transport within glued laminated beams. There is an obvious higher rate of moisture uptake in the outer most moisture probe MC1 followed by MC2 and MC3 during the early cycles, however, with time the inner probes achieve similarly high moisture contents. It is not clear whether the adhesive PRF glue-line has an effect on the moisture content distribution. 


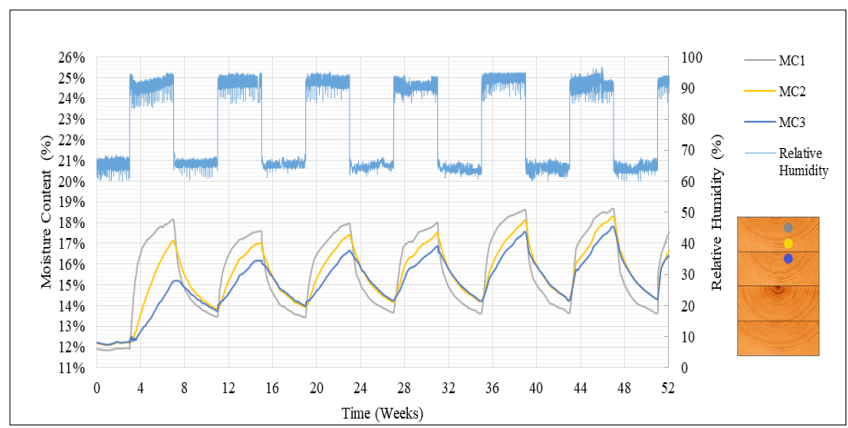

Figure 5: Moisture probe results: $\mathrm{MC1}, \mathrm{MC} 2$ and $\mathrm{MC}$.

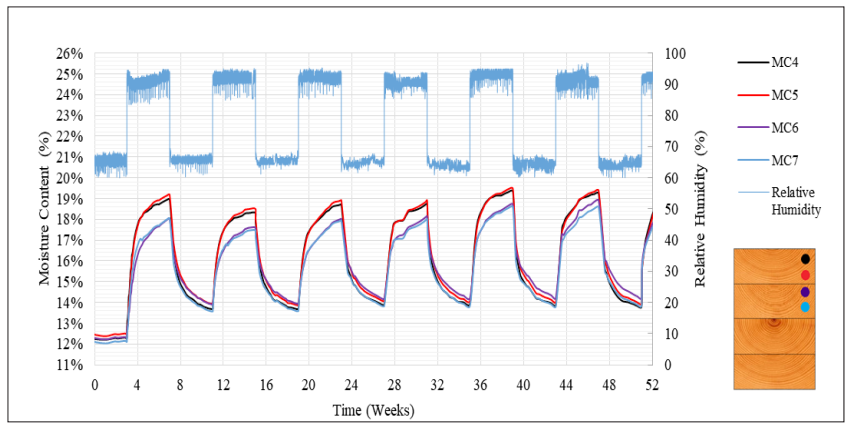

Figure 6: Moisture probe results: MC4, MC5, MC6 and MC7.

The results presented in Figure 6 show the moisture variation within the top two laminations. MC4 and MC5 are located within the top lamination which is subject to moisture transport through the sides of the laminate and also through the top surface of the beam. MC6 and MC7 are located in the second lamination from the top. This second lamination is possibly subject to the effects of the glue-line on moisture transport through the cross-section. As can be seen in Figure 6, the measured moisture content in MC6 and MC7 is lower than MC4 and MC5, however, it is not clear if the PRF adhesive has affected the movement of moisture between laminations.

\section{Measurement of moisture-induced strain results}

The moisture-induced strains were measured using electrical resistance strain gauges on nonloaded, glued laminated beams. The results in Figure 7 and Figure 8 show the strains parallel and perpendicular to the grain, respectively. Each beam is plotted individually to show the variability in results between the different timber elements. The climate conditions implemented have produced approximately repeatable results with each cycle over the first 52 weeks of testing. 


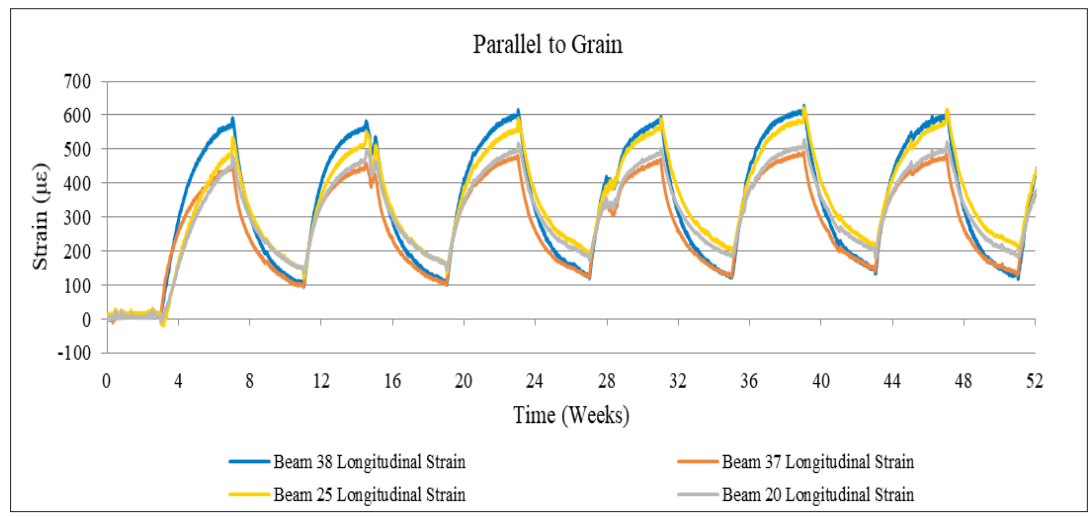

Figure 7: Moisture-induced strain parallel to the grain.

The strain measured in the longitudinal direction remains at approximately $0 \mu \varepsilon$ for the first 3 weeks of the test after which the relative humidity is changed from $65 \% \pm 5 \%$ to $90 \% \pm 5 \%$. This change in relative humidity causes a sudden increase in strain due to the increasing moisture content of the beams. The opposite is seen as the relative humidity is changed from $90 \% \pm 5 \%$ to $65 \% \pm 5 \%$ with a sudden decrease in the moisture-induced strain during the desorption phase of the cycle. After the first cycle, the moisture-induced strain ranges from approximately $100 \mu \varepsilon$ to $600 \mu \varepsilon$. It can be seen that once moisture cycling begins the mean moisture-induced strain never falls below $100 \mu \varepsilon$. This is believed to be a result of the moisture content hysteresis of timber in cyclic climates.

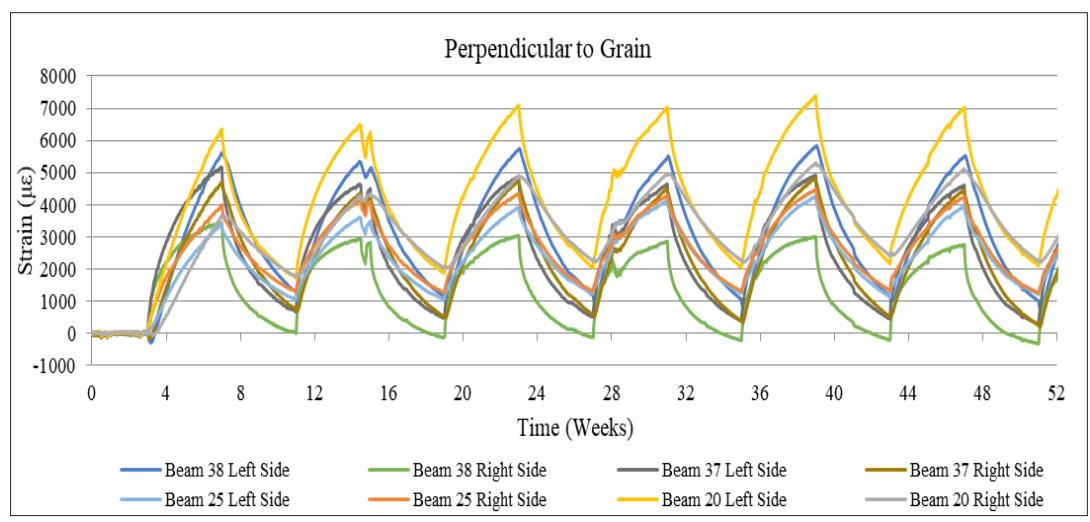

Figure 8: Moisture-induced strain perpendicular to the grain.

As expected, the moisture-induced strains measured perpendicular to the grain are orders of magnitude greater than those measured in the longitudinal direction. There is also a large variation in the strain results measured perpendicular to the grain. The moisture-induced strain ranges from approximately $0 \mu \varepsilon$ to $6500 \mu \varepsilon$ during each moisture cycle. This range of strain measurement can be attributed to the inherent variability in timber affecting material properties through the cross-section. The material orientation has also been shown to have a significant effect on moisture-induced strains (Angst and Malo 2012). Small abnormalities within the measured strains at 15 weeks and 28 weeks can be attributed to a thermostat failure within the conditioning chamber resulting in variations from the set constant temperature of $20^{\circ} \mathrm{C} \pm 2^{\circ} \mathrm{C}$.

\section{Numerical analysis}

As discussed previously, moisture transfer in wood can be described using Fick's law of mass diffusion. Fick's law is analogous to Fourier's law for heat conduction and this analogy is exploited 
using Abaqus FEA software. The use of this thermal-hygro analogy has been used to describe the moisture vapour transport from the surrounding environment through the surface of the timber in many studies (Siau 1984, Siau and Avramidis 1996, Yoon et al. 2007, Fragiacomo et al. 2011). This similarity becomes clear when one compares Fick's law of mass diffusion (Equation 1) to Fourier's law of heat conduction (Equation 4), which in a three-dimensional form is written as:

$$
\frac{\partial T}{\partial t}=k_{x}\left(\frac{\partial^{2} T}{\partial x^{2}}\right)+k_{y}\left(\frac{\partial^{2} T}{\partial y^{2}}\right)+k_{z}\left(\frac{\partial^{2} T}{\partial z^{2}}\right)
$$

Where:

- $\quad \mathbf{x}, \mathbf{y}, \mathbf{z}$ - principal material directions

- $\quad \mathbf{k}$ - thermal conductivity (W/mK)

- $\quad$ T - temperature $\left({ }^{\circ} \mathrm{C}\right)$

In this study, coupled thermal-displacement elements are used exploiting the thermal-hygro analogy described previously. The governing equations allow diffusion coefficients and moisture content to replace thermal conductivity and temperature. Moisture-dependent radial and tangential diffusion coefficients are applied as a material property within Abaqus FEA software. In the developed model of the glued laminated beam described previously, the movement of moisture is constrained to 2-dimensions in the radial and tangential direction. Sealed ends prevent the movement of moisture in the longitudinal direction. This condition is commonly found in practical applications within timber construction and design. The sorption hysteresis is taken into account when defining the relative humidity boundary conditions. The equations needed to describe the moisture transport from the surrounding environment into the wood are implemented into the Abaqus software using a DFLUX user subroutine. In this user subroutine, the magnitude of moisture transport through the surface is defined using Equation 5 (Hanhijärvi 1995a, Fortino et al. 2009, Hassani et al. 2015). The transport of moisture is proportional to the difference between the equilibrium moisture content of the surface of the timber and the equilibrium moisture content of the timber corresponding to the relative humidity of the surrounding environment.

$$
q_{n}=S_{u}\left(\phi_{e q}-\phi_{s u r f}\right)=\rho S_{u}\left(u_{e q}-u_{s u f f}\right)
$$

Where:

- $\mathbf{q}_{\mathrm{n}}$ - moisture transport across the boundary $\left(\mathrm{kg} / \mathrm{m}^{2} \mathrm{~s}\right)$

- $\quad \mathbf{S}_{\mathbf{u}}$ - surface emission coefficient $(\mathrm{m} / \mathrm{s})$

- $\phi_{\text {surf }}$ - moisture concentration of the timber surface $\left(\mathrm{kg} / \mathrm{m}^{3}\right)$

- $\phi_{\mathrm{eq}}$ - equilibrium moisture concentration of timber corresponding to the relative humidity of the surrounding environment $\left(\mathrm{kg} / \mathrm{m}^{3}\right)$

- $\quad \boldsymbol{\rho}$ - density at $0 \%$ moisture content $\left(\mathrm{kg} / \mathrm{m}^{3}\right)$

- $\quad \mathbf{u}_{\text {surf }}$ - moisture content on the timber surface (\%)

- $\quad \mathbf{u}_{\mathrm{eq}}$ - equilibrium moisture content of timber corresponding to the relative humidity of the surrounding environment (\%)

The equilibrium moisture content of the timber, $u_{e q}$, corresponding to the relative humidity of the surrounding environment is calculated using the sorption isotherms determined from experimental tests tabulated in Table 1. During a period of increasing moisture content due to an increase in relative 
humidity, the equilibrium moisture content will correspond to the moisture content along the adsorption curve at the increased relative humidity value. During a period of decreasing moisture content due to a reduction in relative humidity, the equilibrium moisture content will correspond to the moisture content along the desorption curve at the reduced relative humidity value.

The surface emission coefficient, $S_{u}$, defines the rate of moisture content exchange across the boundary. Similarly to the diffusion coefficients, this material property is a function of moisture content $(u)$. The value used in this model of $3,2 \times 10^{-8} \mathrm{e}^{4,0 u} \mathrm{~m} / \mathrm{s}$ was previously reported by Hanhijärvi (1995b). It is worth noting that this is a simplified model focusing on vapour transport and neglects several internal transport processes that take place during moisture change within timber, nevertheless, it has been proven to work well for engineering purposes below the fibre saturation point (Häglund 2007).

The effect of a $0,1 \mathrm{~mm}$ thick glue-line on moisture transport is examined in this model. The moisture content distribution for both a fully permeable and impermeable glue-line are examined. The numerical model presented has been developed implementing the experimentally determined the equilibrium moisture content as a function of relative humidity and the swelling and shrinkage characteristics.

\section{Numerical simulation of moisture transport in glulam}

To examine the moisture transport through the cross-section of the laminated beam, a 2-dimensional moisture transport model was created. This simplification to two dimensions is justified as the ends of the beam are sealed. The beams are also sealed along the bottom surface and therefore moisture exchange is limited to the top surface and both sides of each beam as illustrated in Figure 9. The model comprises four timber laminations separated by adhesive glue-lines. The model mesh consisting of 3536 heat transfer DC2D4 elements was determined using a mesh sensitivity study. The glue-lines were modelled as either fully permeable or impermeable in order to examine the effect of the gluelines on moisture transport in glued laminated beams. The moisture content dependent radial and tangential diffusion coefficients previously presented by Fortino et al. (2009) were used in this study. In order to implement the direction dependent diffusion coefficients, a local cylindrical coordinate system was defined for each lamination. These laminations are cylindrically orientated about the pith to best replicate the orthotropic nature of timber. The pith was centered along the top surface of each lamination.

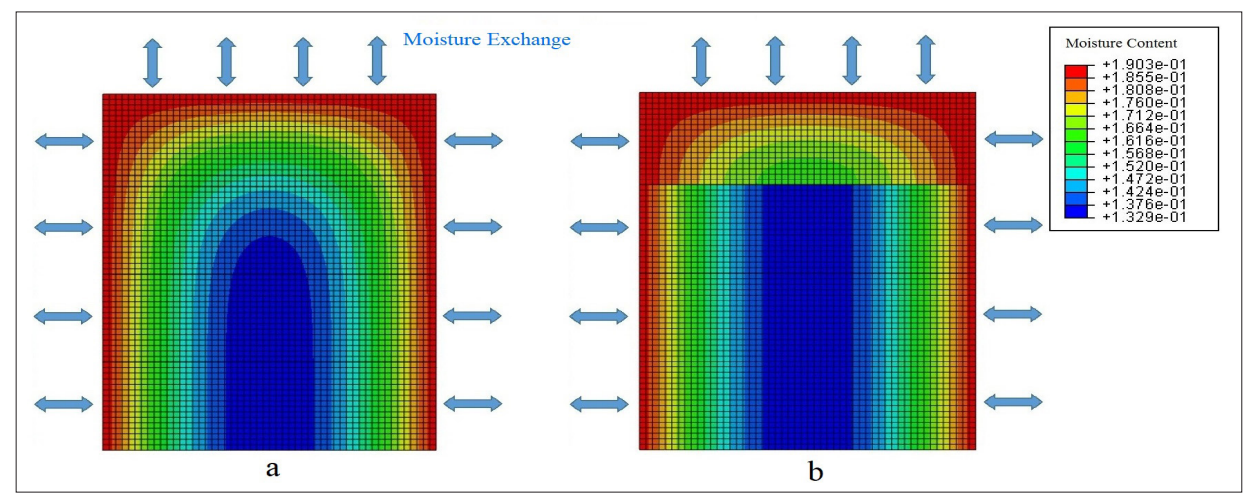

Figure 9: 2-D FEM model, moisture content distribution at 7 weeks: a) fully permeable glue-line b) fully impermeable glue-line.

The effect of the adhesive glue-line on moisture transport in the glulam beam after seven weeks can be seen in Figure 9. In Figure 9a the glue-line is assumed to be fully permeable whereas in Figure $9 \mathrm{~b}$ the glue-line is modelled as fully impermeable. The main differences between the model predictions occur in the top two laminations. When the fully impermeable glue-line is modelled, the transport of 
moisture is impeded limiting all three lower laminations to 1-dimensional diffusion leading to reduced moisture transport in the second lamination. The moisture content distribution through the crosssection was calculated with time examining both glue-line conditions. The appropriate node positions corresponding to moisture probe locations (MC1-MC11) were identified.

In Figure 10 the experimental measurements from moisture probe $\mathrm{MC} 1$ are compared to the simulated results from the numerical model. The numerical results for both the fully permeable glueline and impermeable glue-line condition are plotted together with the experimental results of the first 52 weeks of testing. It can be seen that the numerical results of both the permeable glue-line and impermeable glue-line condition adequately match the experimental data for $\mathrm{MC} 1$ which is located within the top lamination, $10 \mathrm{~mm}$ from the top surface and $40 \mathrm{~mm}$ from the side of the beam (Figure 2). The glue-line has an insignificant effect on the movement of moisture at the MC1 position, as this point is close to the top surface of the beam. The largest simulated differences in moisture content as a result of the impermeable glue-line occur during the initial moisture cycles and these differences diminish with repeating cycles.

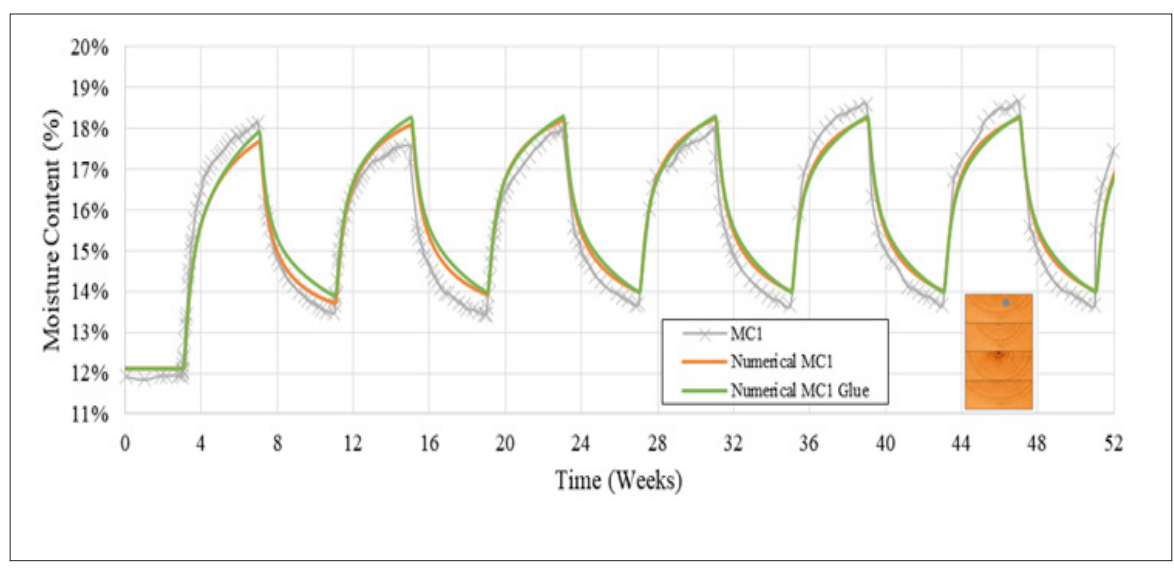

Figure 10: Probe MC1, Experimental vs numerical results.

Similar results are seen in all moisture probes close to the surface of the timber and are accurately modelled. MC6 is one such probe which is in the second lamination and positioned at a depth of 10 $\mathrm{mm}$ from the surface (Figure 2). The experimental and numerical results of probe MC6 show good agreement with one another (Figure 11) similar to MC1. MC6 has also shown a better correlation coefficient when comparing the experimental data to that of the model with a fully permeable glueline, however, the main differences occur during the first 3 cycles and diminish with repeating moisture content cycles.

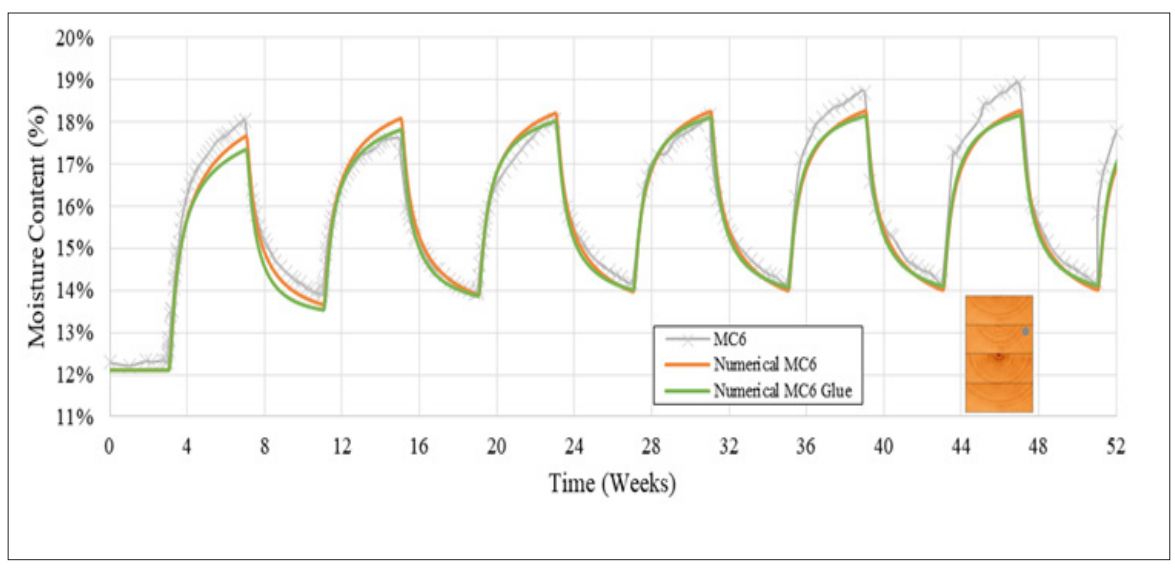

Figure 11: Probe MC6, Experimental vs numerical results. 
The model has shown excellent agreement with moisture content measurements close to the surface, however, the predictions at greater depths are less precise. MC2 and MC3 are located at greater depths as seen in Figure 2. The experimental and numerical results for moisture probe MC2 are plotted in Figure 12. Moisture probe MC2 is located in the top lamination, $25 \mathrm{~mm}$ from the top surface of the beam and $40 \mathrm{~mm}$ from the side. The increased depth of this moisture probe has resulted in a more gradual increase in moisture content at this MC2 position. The numerical and experimental results show similar trends of increasing and decreasing moisture content with repeated moisture cycling. The numerical results show a greater difference between the fully permeable and impermeable glue-line, however, these differences are largest in the initial moisture cycles and reduce with repeated moisture cycling. There is a phase lag between the experimental and numerical results presented. Experimentally, a more rapid change in moisture content was observed at the beginning of each desorption cycle. Under ideal conditions, a slight delay in moisture content change would be expected as simulated by the model. This abrupt change in moisture content is believed to be as a result of the multiple factors influencing the observed moisture content with depth using the resistive method. However, considering the factors influencing the probes and possible contact issues with time, the experimental results provide a reliable estimation of the true moisture content at each measurement point.

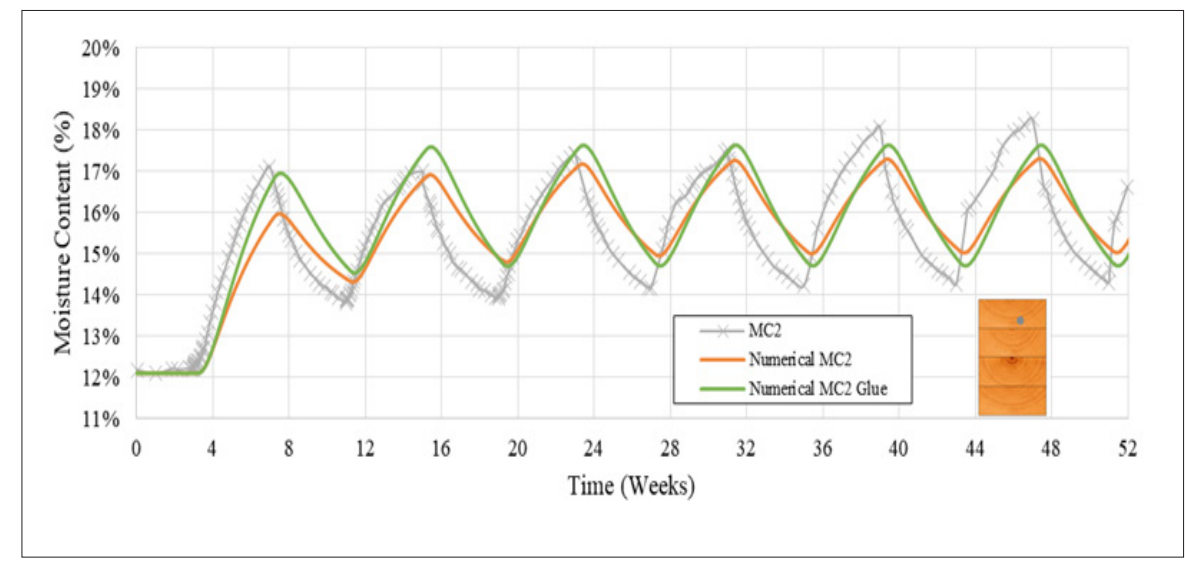

Figure 12: Probe MC2, Experimental vs numerical results.

There is a similar trend when examining moisture probe MC3, which is located within the second lamination from the top $37,5 \mathrm{~mm}$ from the top surface and $40 \mathrm{~mm}$ from the side of the beam. The simulated results again show a similar trend of increasing moisture content during early moisture cycle. Given the position of this probe, MC3 is expected to be heavily influenced by the glue-line. This is apparent when examining the simulated results in Figure 13. The model has shown good agreement during the adsorption phase; however, experimental results have shown a more rapid decrease in moisture content during desorption phase. This would indicate differences between the diffusion coefficients during adsorption and desorption. It would be beneficial to incorporate different diffusion coefficients to further refine the model. It is also worth noting that moisture transport in timber is not the solely attributed to moisture diffusion and other mechanisms may contribute to the flow of moisture. 


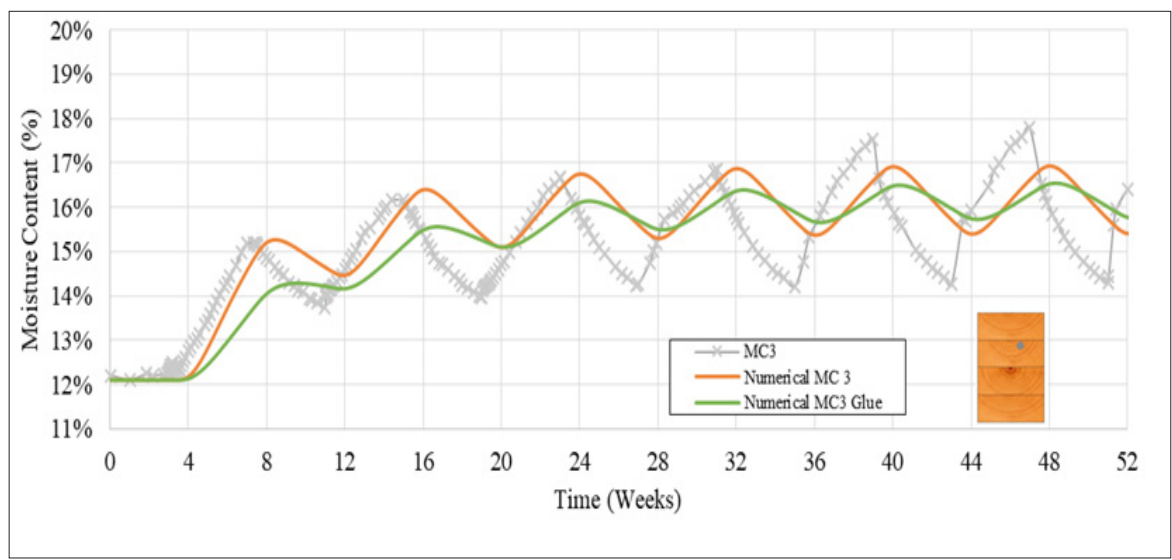

Figure 13: Probe MC3, Experimental vs numerical results.

When the numerical simulations with a fully permeable and impermeable glue-line are compared to the experimental data from moisture probes MC2 and MC3, a higher correlation is observed in the fully permeable model. In moisture probe MC2, a correlation coefficient of 0,76 was observed when comparing the experimental data to that of the model with a fully permeable glue-line compared to a correlation coefficient of 0,66 when the experimental data was compared to that of the model with an impermeable glue-line. Similar trends were seen when comparing results from moisture probe MC3. A correlation coefficient of 0,56 was observed when comparing the experimental data to that of the model with a fully permeable glue-line compared to a correlation coefficient of 0,50 when the experimental data was compared to that of the model with an impermeable glue-line. This would indicate that the inclusion of the glue-line within the model may add to the computational time and not necessarily contribute to additional accuracy. It must also be considered that the size of the beams in the test programme is $125 \mathrm{~mm}$ x $98 \mathrm{~mm}$ and the effect of the glue-line may be more significant in larger sections.

\section{Numerical simulations of moisture-induced strain}

Moisture-induced strains in non-loaded glued laminated beams in a variable climate have been previously presented. The results show relatively consistent and repeatable fluctuations in moistureinduced strain with repeated moisture content cycles. The strains were measured in the longitudinal and perpendicular to grain directions of each instrumented beam.

A 3-dimensional coupled hygro-mechanical model has been developed to simulate moistureinduced strain in non-loaded glued laminated beams incorporating material properties specific of fastgrown Sitka spruce. To reduce the computational time, it is assumed that all material properties and annual ring orientation remain uniform in the longitudinal direction. This permits a shortened slice of the beam to be modelled (Hassani et al. 2015) and the boundary conditions allow for free expansion and contraction. A $60 \mathrm{~mm}$ slice of the entire beam comprising of four laminations each measuring $98 \mathrm{~mm} \times 125 \mathrm{~mm}$ is modelled as shown in Figure 14. This coupled moisture-displacement, model consists of 95008 -noded thermally coupled C3D8T elements. The mesh size was determined from a mesh sensitivity study based on convergence of the moisture content and strain output of the coupled moisture-displacement model. Each of the four laminations is assigned material properties in a local cylindrically orientated coordinate system. Results from the numerical simulation of moisture transport suggest the addition of the fully impermeable glue-line in the model will add to the computational time and will not necessarily provide any additional accuracy and, hence, has been omitted from this model. The beam was subjected to variable relative humidity cycles similar to that reported in the experimental tests. The humidity cycles were implemented within Abaqus using a user-defined DFLUX subroutine 
as described previously.

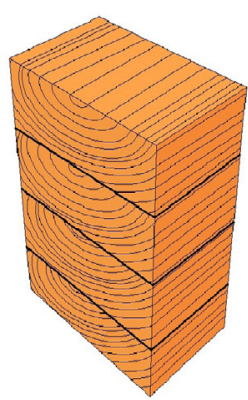

a

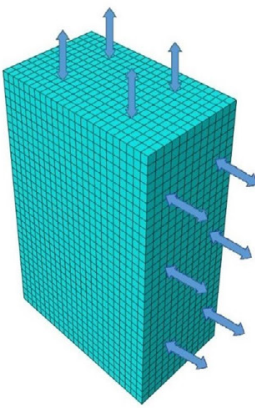

$\mathrm{b}$

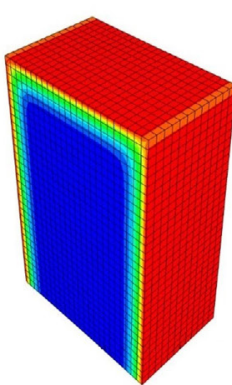

C

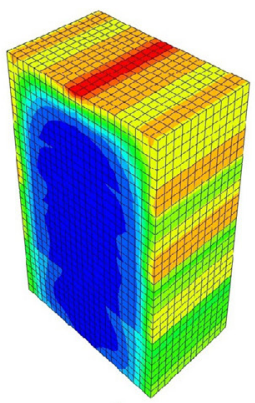

d

Figure 14: $60 \mathrm{~mm}$ slice through the glued laminated beam, a) Timber section, b) Model mesh, c) moisture content distribution and d) moisture-induced strain distribution.

In Figure 14, the idealised symmetric case where the pith of each timber lamination is situated in the centre along the top surface of each lamination is presented. The moisture content distribution at an instant in time can be seen in Figure 14c and the corresponding strain distribution can be seen in Figure $14 \mathrm{~d}$. The strains are significantly higher along the glue-lines as expected due to the different material properties and the change in material orientation at this junction. These strain discontinuities can lead to the development of cracks between adjacent laminations due to the low tensile strength perpendicular to grain with repeated moisture cycling. This model assumes an ideal symmetric geometry cylindrically orientated around the pith. This assumption is adequate in practical circumstances, however, the position of the pith within the timber model has been shown to have a significant influence on the strain distribution through each lamination. In a numerical study by Angst and Malo (2012), 35-50\% lower stresses were observed when the piths were located outside the laminations compared to a configuration where piths were located in the laminations. For this reason, a case study of a particular beam (Beam 37) was chosen, mapped and replicated as closely as possible within the FEA model. This mapping process can be seen in Figure 15. The tangential material orientation input within the Abaqus FEA environment can be seen to be in agreement with the mapped beam (Figure 15c).

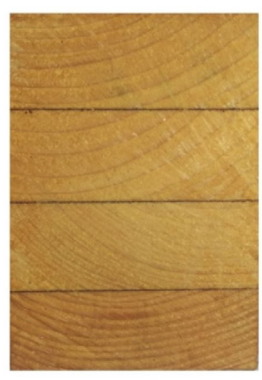

a

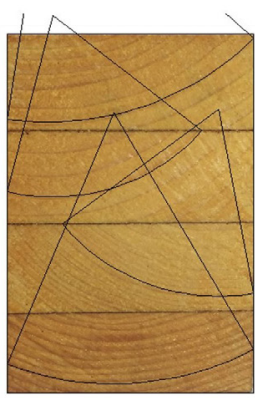

b

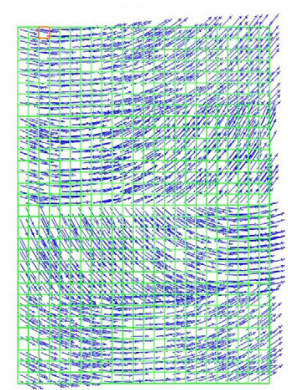

Figure 15: Mapping material orientation: a) Beam 37 Ring orientation, b) mapping lamination orientation, c) material orientation within Abaqus FEA software (tangential direction illustrated).

The parallel to grain results of the numerical model are presented in Figure 16 together with the experimental data previously presented. The mapped case and the idealised case produced similar 
results as the orientation of the longitudinal direction remained constant. For this reason, only the mapped case is presented with all the measured parallel to grain strains in the longitudinal direction. The relatively high longitudinal swelling/shrinkage coefficient $(0,0122)$ appears to adequately predict the response of the timber in this cyclic climate over a 52-week period. Although this swelling/shrinkage coefficient is difficult to measure, the average value is deemed suitable when describing the swelling/ shrinkage characteristics in a cyclic climate.

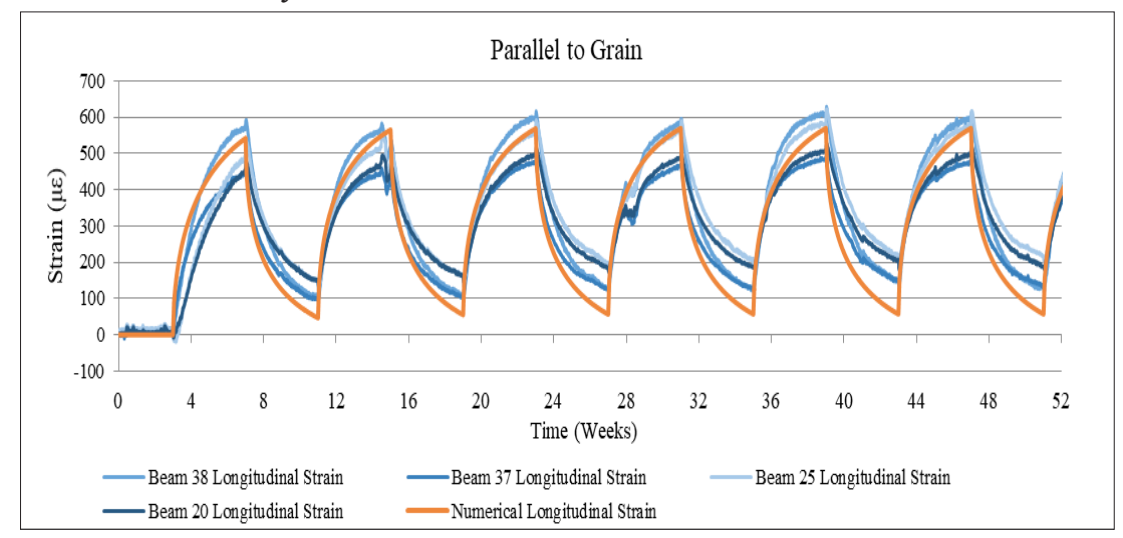

Figure 16: Parallel to grain strain for the first 52 weeks.

The perpendicular to grain results of the numerical models are presented in Figure 17 together with the experimental data for Beam 37. The numerical strain measurement presented is an average of the simulated results on the left and right side of the beam model. The numerical results of both the idealised case and mapped model case are presented in Figure 17 for comparison purposes. The mapped material orientation has produced a more accurate prediction of the perpendicular to grain strain resulting from fluctuating moisture content with time. The perpendicular to grain strains have been adequately predicted using the radial and tangential swelling/shrinkage coefficients of 0,1371 and 0,2525 respectively. The model has been shown to predict with good accuracy, the moisture-induced strain development in specimens subjected to a variable climate in both the longitudinal and tangential directions.

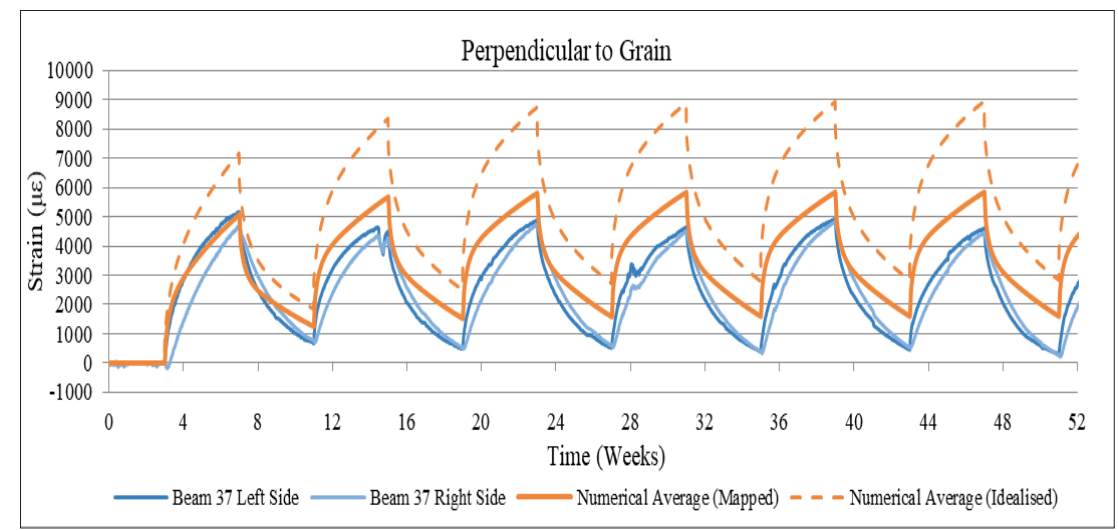

Figure 17: Perpendicular to grain strain for the first 52 weeks. 


\section{CONCLUSIONS}

The understanding of moisture transport within fast-grown Sitka spruce timber members and the moisture-induced strains as a result of cyclic climates are of great importance to researchers and engineers alike. A series of experiments was designed to determine the relevant material properties and their dependency on moisture content. These material properties have been implemented in finite element models to examine moisture diffusion and moisture-induced strains in this fast-grown species with a view to promoting the development and utilisation of this species in the manufacturing of EWPs.

The moisture content hysteresis curve for fast-grown specimens at $20^{\circ} \mathrm{C}$ has been presented and the individual adsorption and desorption isotherms have been characterised. This has provided accurate moisture prediction in both small and large timber specimens subjected to varying relative humidity environments.

The model predicted the moisture content close to the surface with a high level of accuracy. For interior locations, the model predicts the adsorption phase of the moisture cycle accurately but, in the desorption phase, the moisture content gradient is lower than measured values. The accuracy of the model may be improved through the use of different diffusion coefficients for the adsorption and desorption phases. Future work will investigate this further.

The moisture-induced strain has also been accurately predicted with the use of experimentally determined shrinkage/swelling coefficients. The radial and tangential swelling/shrinkage coefficients have adequately predicted the transverse strains measured on non-loaded glued laminated beams. The mean experimentally determined longitudinal swelling/shrinkage coefficient, although difficult to measure and associated with a high standard deviation, accurately predicted the moisture-induced strain in the longitudinal direction. The use of these species-specific swelling/shrinkage coefficients will allow accurate distortion prediction of this material contributing to the development and utilisation of this fast-grown material. Significantly, the accuracy of the model can be greatly increased by carefully defining the orientation of material. This was evident when the location of the pith and cylindrically orientated radial and tangential material directions were accurately defined in the individual laminations. For practical purposes, this precise characterisation might not be feasible but, for validating the model, this is an important action.

The effect of the glue-line on the transport of moisture within glued laminated beams has been examined numerically. The PRF glue-line has been treated as either, a fully permeable or fully impermeable layer. In the long term, the differences in the predicted moisture content with the two approaches do not appear to be significant when examining a glued laminated beam of this size and it appears that the omission of a glue-line from the model is a valid assumption. The significance of this difference may however be increased within larger EWPs and should be examined.

This experimental characterisation of fast-grown Sitka spruce and validated model can be used in the design of EWPs in variable climates. Further work is underway to determine the mechano-sorptive creep effects in glued laminated beams loaded under serviceability conditions.

\section{ACKNOWLEDGEMENTS}

This work has been carried out as part of the project entitled 'Innovation in Irish timber Usage' (project ref. 11/C/207) funded by the Department of Agriculture, Food and the Marine of the Republic of Ireland under the FIRM/RSF/COFORD scheme. The authors would also like to thank ECC Ltd. (Earrai Coillte Chonnacht Teoranta) for supplying all the timber used in this project. The contribution of the technical staff of the College of Engineering and Informatics, NUIG, in particular, Peter Fahy, Colm Walsh and Gerrard Hynes, is acknowledged 


\section{REFERENCES}

Angst, V.; Malo, K. A. 2012. Effect of self-tapping screws on moisture induced stresses in glulam. Engineering Structures 45: 299-306.

Avramidis, S. 1989. Evaluation of "three-variable" models for the prediction of equilibrium moisture content in wood. Wood Science and Technology 23(3): 251-257.

Bengtsson, C. 2001. Variation of moisture induced movements in Norway spruce (Picea abies). Annals of Forest Science 58(5): 568-581.

Bourke, M.; Redington, M.; Moloney, S. 2001. Sitka spruce dried to low moisture content for predictable in-service performance as construction elements', In Proceedings of the 3rd Cost Action E15 Workshop, The drying of softwood species. Helsinki, Finland.

Dai, G.; Ahmet, K. 2001. Long-term monitoring of timber moisture content below the fiber saturation point using wood resistance sensors. Forest Products Journal 51(5): 52-58.

Forsén, H.; Tarvainen, V. 2000. Accuracy and functionality of hand held wood moisture content meters. Technical Research Centre of Finland Espoo, Finland, VTT Publications 420.p79

Fortino, S.; Mirianon, F.; Toratti, T. 2009. A 3D moisture-stress FEM analysis for time dependent problems in timber structures. Mechanics of Time-Dependent Materials 13(4): 333-356.

Fragiacomo, M.; Fortino, S.; Tononi, D.; Usardi, I.; Toratti, T. 2011. Moisture-induced stresses perpendicular to grain in cross-sections of timber members exposed to different climates. Engineering Structures 33(11): 3071-3078.

Gereke, T.; Niemz, P. 2010. Moisture-induced stresses in spruce cross-laminates. Engineering Structures 32(2): 600-606.

Häglund, M. 2007. Moisture content penetration in wood elements under varying boundary conditions', Wood Science and Technology 41(6): 477-490.

Hailwood, A.; Horrobin, S. 1946. Absorption of water by polymers: analysis in terms of a simple model. Transactions of the Faraday Society 42: 84-92.

Hanhijärvi, A. 1995a. Deformation kinetics based rheological model for the time-dependent and moisture induced deformation of wood. Wood Science and Technology 29(3): 191-199.

Hanhijärvi, A. 1995b. Modelling of creep deformation mechanisms in wood. VTT Publications. Technical Research Center of Finland Espoo, Finland.

Hassani, M.M.; Wittel, F.K.; Hering, S.; Herrmann, J. 2015. Rheological model for wood. Computer Methods in Applied Mechanics and Engineering 283: 1032-1060.

Merakeb, S.; Dubois, F.; Petit, C. 2009. Modeling of the sorption hysteresis for wood. Wood Science and Technology 43(7-8): 575-589.

Ormarsson, S.; Cown, D. 2004. Moisture-related distortion of timber boards of radiata pine: Comparison with Norway spruce. Wood and Fiber Science 37(3): 424-436.

Patera, A.; Derluyn, H.; Derome, D.; Carmeliet, J. 2015. Influence of sorption hysteresis on moisture transport in wood. Wood Science and Technology 50(2): 1-25.

Raftery, G.; Harte, A. 2014. Material characterisation of fast-grown plantation spruce. Structures and Buildings 167(6): 380-386.

Sargent, R.; Riley, S.; Schöttle, L. 2010. Measurement of dynamic sorption behaviour of small specimens of Pinus radiata - Influence of wood type and moisture content on diffusion rate. MaderasCienc Tecnol 12(2): 93-103. 
Siau, J. F. 1984. Transport Processes in Wood. Springer, New York, USA.

Siau, J. F.; Avramidis, S. 1996. The Surface Emission Coefficient of Wood. Wood and Fiber Science 28(2): 178-185.

Simo-Tagne, M.; Rémond, R.; Rogaume, Y.; Zoulalian, A.; Bonoma, B. 2016. Sorption behavior of four tropical woods using a dynamic vapor sorption standard analysis system. MaderasCienc Tecnol 18(3): 403-412.

Simpson, W. 1973. Predicting equilibrium moisture content of wood by mathematical models. Wood and Fiber Science 5(1), pp. 41-49.

Skaar, C. 1987. Water in wood. Syracuse University Press, New York, USA.

Srpčič, S.; Srpčič, J.; Saje, M.; Turk, G. 2009. Mechanical analysis of glulam beams exposed to changing humidity. Wood Science and Technology 43(1-2): 9-22.

Svensson, S.; Toratti, T. 2002. Mechanical response of wood perpendicular to grain when subjected to changes of humidity. Wood Science and Technology 36(2): 145-156.

Taylor, G.D.; West, D.J. 1990. Use of stainless steel pins for in-situ measurement of moisture contents in the structural members of a glulam framed church. Journal of the Institute of Wood Science 12(2): 71-76. $19-28$.

Toratti, T. 1993. Long Term Deflection of Timber Beams. Journal of Structural Mechanics 26(3):

Wadsö, L. 1993. Studies of Water Vapor Transport and Sorption in Wood, Division of Building materials, Lund University. PhD Thesis, Division of Building materials, Lund University, Sweden.

Wimmer, R.; Kläusler, O.; Niemz, P. 2013. Water sorption mechanisms of commercial wood adhesive films. Wood Science and Technology 47(3): 763-778.

Yoon, S.; Han, B; Wang, Z. 2007. On moisture diffusion modeling using thermal-moisture analogy. Journal of Electronic Packaging 129(4): 421-426.

Zongying, F.; Zhao, J. Lv, Y.; Huan, S.; Cai, Y. 2016. Stress characteristics and stress reversal mechanism of white birch (Betula platyphylla) disks under different drying conditions. Maderas-Cienc Tecnol 16(2): 361-372. 